\title{
Experimental research on heat transfer characteristics of Dimple plate heat exchanger
}

\author{
Ji Changfa,Wu Liangliang,Li Jiawei, Wang Xiaoxia
}

(School of Energy and engineering, Xi'an University of Science and Technology, Xi'an 710054, China)

Keywords: Heat exchanger; Dimple plate; Heat transfer characteristics; Flow resistance.

Abstract: In this paper, we use experiment to work on our own design of the dimple plate heat exchanger and the experimental result is compared with the heat transfer characteristics of the flat plate under the same experimental conditions. The test result shows that, under the given inlet temperature condition, heat transfer is closely related to Reynolds. At the low Reynolds number, the intensive heat transfer effect of dimple plate is not obvious. With the increase of Reynolds number, dimple plate's wall heat transfer coefficient and heat transfer increase gradually, water outlet temperature gradually decrease, the flow resistance will also increase at the same time. The dimple plate has the effect of strengthening heat transfer, but also increases the resistance, in practical application process required to optimize the analysis, to find out a dimple plate with good matching effect between heat transfer enhancement and pressure loss.

\section{INTRODUCTION}

Plate heat exchanger having a high heat transfer coefficient,compact,easy to take apart and wash etc, it is an efficient, compact heat transfer equipment and it has been widely used in industrial and agricultural production. In order to strengthen heat transfer, plate heat exchanger is made of suppress a variety of corrugated sheet metal heat exchanger plates piled up, however, due to the roughness increases, the flow resistance is relatively large ${ }^{[1,2]}$. There are many factors affecting the effects of plate heat exchanger heat transfer, corrugation angle, wave height 、 wave distance are three main factors influence plate heat transfer and flow resistance ${ }^{[3,4]}$. Therefore, it is necessary to find the heat exchanger which is more matched with heat transfer performance and flow resistance, it has been the main directions of optimization and improvement. This paper, we proposes a new dimple plate in unit as shown in figure1, and experimental research on its flow and heat transfer performance. Dimple plate made of pure copper (also called copper), its physical parameters $: \rho=8900 \mathrm{~kg} / \mathrm{m}^{3}$, specific heat $C_{\mathrm{D}}=406 \mathrm{~J} /(\mathrm{kg} \cdot \mathrm{K})$, coefficient of thermal conductivity $\lambda=385 \mathrm{~W} /(\mathrm{m} \cdot \mathrm{K})$ specification dot diameter (D) $12 \mathrm{~mm}$ (dimple diameter), dotheights $(\mathrm{H})$ $4 \mathrm{~mm}$ (dimple heights), dotdistance (L) $21 \mathrm{~mm}$ (dimple distance), length $\times$ width $=1000 \mathrm{~mm} \times 200 \mathrm{~mm}$.

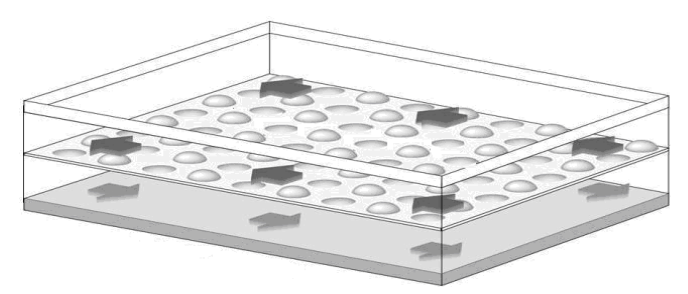

(a) Experiment with a dimple plate

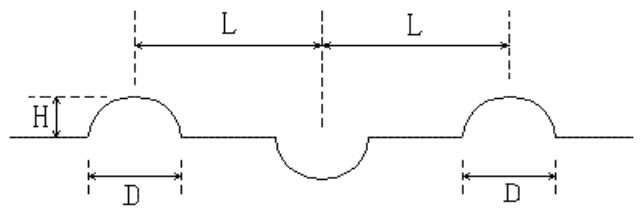

(c) Dimple plate geometry size

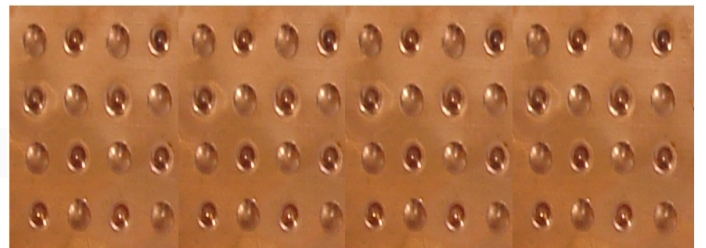

(b)Dimple plate heat exchanger

Fig.1 Dimple plate heat exchanger 


\section{EXPERIMENTAL APPARATUS AND DATA PROCESSING METHOD}

\section{Experimental apparatus}

This paper is intended to build the experimental platform as shown in Figure 2.As shown in the comparison chart, the experiment is made of the following major systems:

1) Water circulation system:the system is composed of two parts, hot water circulation system and cold water circulation system, cold and hot water reverse flow, lower cavity with cold water, the upper chamber is in the hot water.

2) Control system:relay, heater, temperature gauge. In the experiment, the electric heating rod in a controllable heat bucket is mainly controlled by the relay and the digital controller.

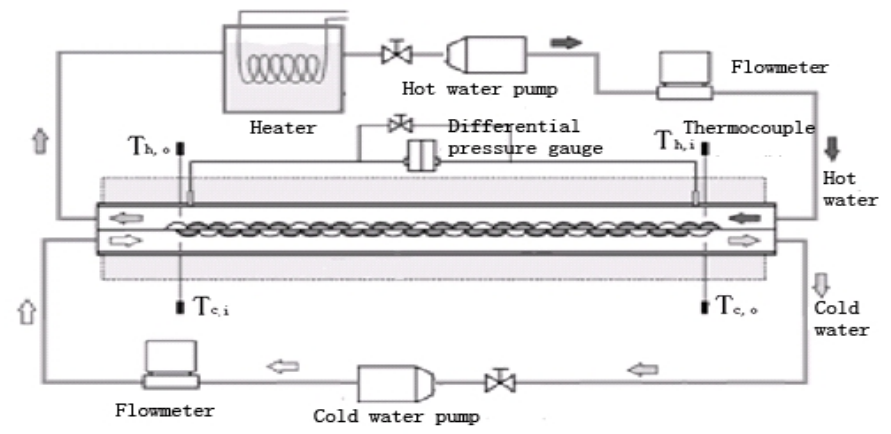

Fig.2 Test setup for coefficient of heat transfer

3) Temperature measurement system:According to the needs of the experiment, the main parameters of measurement: the temperature of the cold, hot water, inlet and outlet of the experimental section. In the experiment, 8 temperature measuring points are arranged, four of the thermocouples are placed in cold,hot water inlet and outlet, and the remaining four are arranged in the out side of the box body. For each measuring point is used after calibration of the copper-constantan thermocouple and Sixteen temperature patrol instrument for temperature measurement.

\section{Data processing method}

In the process of measuring the dimple plate's surface heat transfer coefficient $h$, we intends to adapt the following methods:

According to the calculation formula provided by the literature ${ }^{[5]}$, the total heat exchange:

$$
Q=U A \mathrm{~T}_{\mathrm{lm}}
$$

$\mathrm{U}$ and $\mathrm{T}_{\mathrm{lm}}$ in the formula respectively is the heat transfer coefficient and the logarithmic temperature difference, the $\mathrm{A}$ is the heat exchange area, and:

$$
\begin{gathered}
\mathrm{U}=\frac{1}{1 / \mathrm{h}_{\mathrm{c}}+\mathrm{t} / \mathrm{k}+1 / \mathrm{h}_{\mathrm{h}}} \\
\Delta \mathrm{T}_{\mathrm{lm}}=\frac{\Delta \mathrm{T}_{2}-\Delta \mathrm{T}_{1}}{\ln \left(\Delta \mathrm{T}_{2} / \Delta \mathrm{T}_{1}\right)}\left[\frac{\Delta \mathrm{T}_{1} \equiv \mathrm{T}_{\mathrm{h}, \mathrm{i}}-\mathrm{T}_{\mathrm{c}, \mathrm{o}}}{\Delta \mathrm{T}_{2} \equiv \mathrm{T}_{\mathrm{h}, \mathrm{o}}-\mathrm{T}_{\mathrm{c}, \mathrm{i}}}\right]
\end{gathered}
$$

$T_{c . i}, T_{c . o}, T_{h . i}, T_{h . o}$ in the formula respectively is the temperature of the hot and cold fluids. $h_{c}$ and $h_{h}$ respectively is the surface heat transfer coefficient of the hot fluid side, $\mathrm{K}$ is the thermal conductivity of dimple plate. Heat transfer can be obtained by the following formula ${ }^{[6,7]}$

$$
\mathrm{Q}=m_{c} c_{p, c}\left(T_{c, o}-T_{c, i}\right)=m_{h} c_{p, h}\left(T_{h, i}-T_{h, o}\right)
$$

When the hot and cold fluid in the plate with the same flow state (in the case without considering the temperature difference), can be considered $h_{c}$ and $h_{h}$ are equal, so formula (2) can be written:

$$
U=\frac{1}{2 / \mathrm{h}+\mathrm{t} / \mathrm{k}}\left(\mathrm{h}_{\mathrm{c}}=\mathrm{h}_{\mathrm{h}}=\mathrm{h}\right)
$$

In the formula of $\mathrm{h}$ is the surface heat transfer coefficient, and the $\mathrm{h}$ can be obtained by the following formula:

$$
\mathrm{h}=\frac{2}{1 / \mathrm{U}-\mathrm{t} / \mathrm{k}}=\frac{2}{\mathrm{~A} \Delta \mathrm{T}_{\mathrm{lm}} / \mathrm{Q}-\mathrm{t} / \mathrm{k}}
$$

Experiments are carried out on the same size of dimple plate and flat plate respectively,and adapt the method of variable water flow. The hot water flow rate is controlled at $0.05 \mathrm{~m} / \mathrm{s}, 0.1 \mathrm{~m} / \mathrm{s}, 0.2$ 
$\mathrm{m} / \mathrm{s}, 0.4 \mathrm{~m} / \mathrm{s}, 0.6 \mathrm{~m} / \mathrm{s}, 0.8 \mathrm{~m} / \mathrm{s}, 1 \mathrm{~m} / \mathrm{s}$, then under different inlet temperatures $\left(50^{\circ} \mathrm{C}\right.$ and $\left.70^{\circ} \mathrm{C}\right)$, and measure temperature of the corresponding export 、import and export pressure, then compare the corresponding parameters.

\section{EXPERIMENTAL RESULTS AND ANALYSIS}

The thermodynamic parameters of the water temperature is $50^{\circ} \mathrm{C}$ : Density $\rho=988 \mathrm{~kg} / \mathrm{m}^{3}$, Specific heat $\mathrm{C}_{\mathrm{p}}=4174 \mathrm{~J} / \mathrm{kg} \cdot \mathrm{K}$, Thermal conductivity $\lambda=0.648 \mathrm{~W} /(\mathrm{m} \cdot \mathrm{K})$, Kinematic viscosity coefficient $v=0.556 \times 10^{-6} \mathrm{~m}^{2} / \mathrm{s}$, Prandtl number $\mathrm{P}_{\mathrm{r}}=3.54$; The thermodynamic parameters of the water temperature is $70^{\circ} \mathrm{C}$ :Density $\rho=977.7 \mathrm{~kg} / \mathrm{m}^{3}$, Specific heat $\mathrm{C}_{\mathrm{p}}=4187 \mathrm{~J} /(\mathrm{kg} \cdot \mathrm{K})$, Thermal conductivity $\lambda=0.668 \mathrm{~W} /(\mathrm{m} \cdot \mathrm{K})$, Kinematic viscosity coefficient $v=0.415 \times 10^{-6} \mathrm{~m}^{2} / \mathrm{s}$, Prandtl number $\mathrm{P}_{\mathrm{r}}=2.55$;

\section{Comparison of outlet temperature $T$}
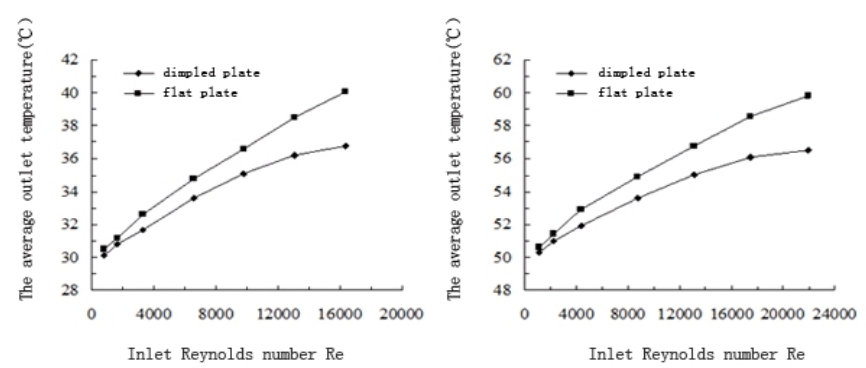

$\begin{array}{lll}\text { (a)Hot water inlet temperature } 50^{\circ} \mathrm{C} & \text { (b) Hot water inlet temperature } 70^{\circ} \mathrm{C}\end{array}$

Fig.3 The change curve of average outlet temperature $\mathrm{T}$ dimpled plate and plate with different entrance temperature entrance Reynolds number Re

Can be seen from Figure 3, when the Reynolds number Re is less than 2300, the cold side outlet temperature difference of dimpled plate and flat plate is not big. With the increasing of the Reynolds number, the dimpled plate and flat plate cold water outlet temperature difference is also increased.This shows that at low velocity, dimpled plate for fluid disturbance is not obvious, the extent of damage to the boundary layer is not enough; with the increase of flow velocity, the disturbance caused by dimpled plate to fluid flow is becoming more and more strong, the heat transfer effect is intensified.In the meantime, can be seen from Figure 3, the inlet temperature of different hot water has little effect on the two kinds of plate heat transfer. But the change trend is consistent.

\section{Comparison between heat transfer $Q$ and surface heat transfer coefficient $h$}

The size of the surface heat transfer coefficient and the heat transfer is closely related to the physical property and flow velocity of the fluid, and the shape, size and arrangement of the heat exchange surface.In order to determine the average heat transfer coefficient between the fluid and the surface of the heat exchanger plate, this article selects Newton cooling formula.

At $50^{\circ} \mathrm{C}$ and $70^{\circ} \mathrm{C}$ inlet temperature, under different Reynolds number, the variation curves of $\mathrm{Q}$ and the surface heat transfer coefficient $h$ are shown in figure 4 and figure 5.
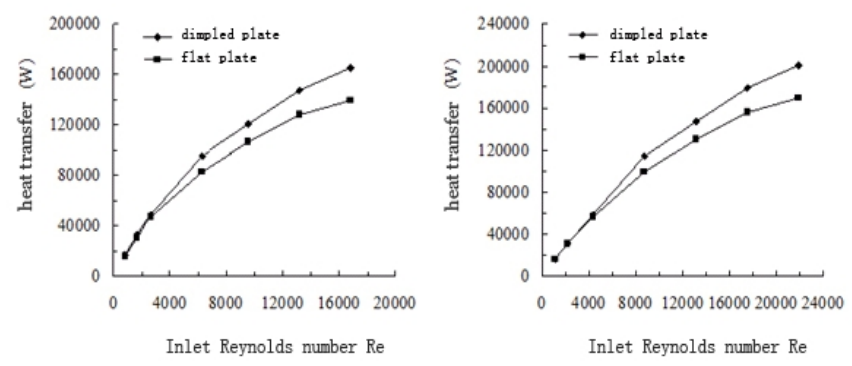

(a)Hot water inlet temperature $50^{\circ} \mathrm{C}$

(b) Hot water inlet temperature $70^{\circ} \mathrm{C}$

Fig.4 Comparison of different entrance temperature dimpled plate and flat wall heat transfer Q 

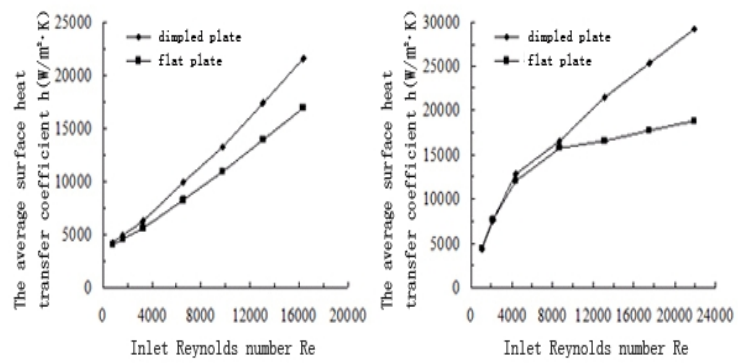

(a)Hot water inlet temperature $50^{\circ} \mathrm{C} \quad$ (b) Hot water inlet temperature $70^{\circ} \mathrm{C}$

Fig.5 Comparison of different entrance temperature dimpled plate and flat surface heat transfer coefficient

Can be seen from Figure 4, at low Reynolds number, heat transfer increase of the dimpled plate is not obvious, with the increase of Reynolds number, spoiler strength is also enhanced, and the secondary reflux continues to scour the wall. The heat transfer between the fluid and the wall is enhanced, strengthen the effect of heat transfer. Can be seen from Figure 5, within the range of $\mathrm{Re}=9810$ to 16350 , surface heat transfer coefficient of dimpled plate is significantly higher than the flat plate, this conclusion is consistent with the conclusion of Figure 4 that the change of Q consistent with the change of Re number. And can be seen from Figure 4 and 5, different hot water inlet temperature has little effect on the two kinds of plate heat transfer and heat transfer coefficient.

\section{Compare Nusselt number and pressure drop $\Delta P$ and the drag coefficient $f$}

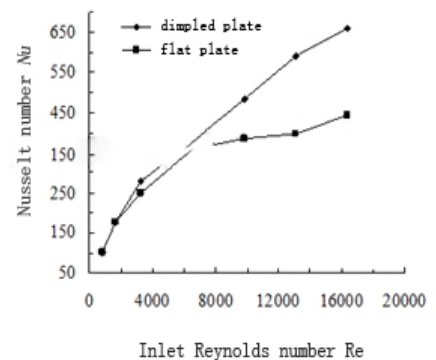

(a)Hot water inlet temperature $50^{\circ} \mathrm{C}$

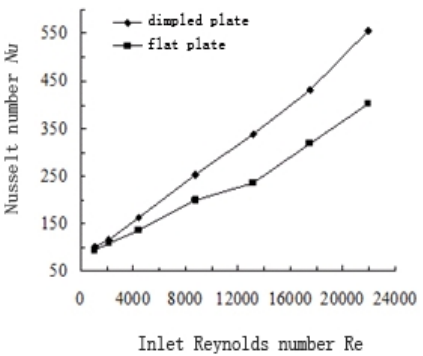

(b) Hot water inlet temperature $70^{\circ} \mathrm{C}$

Fig.6 Comparative number dimpled plate and flat $\mathrm{Nu}$ different entrance temperature

Can be seen from Figure 6, dimpled plate and flat plate wall Nusselt number is increase with increasing Reynolds number, while the increasing amplitude of dimpled plate is more than flat plate. The bigger Reynolds number, the greater increase of amplitude, this is because with the increase of the Reynolds number, convection enhanced, the thermal boundary layer is destroyed by the disturbance of dimpled plate,at the same time, the secondary impact of fluid caused the boundary layer to become thinner, and the heat transfer in the vicinity was significantly enhanced.

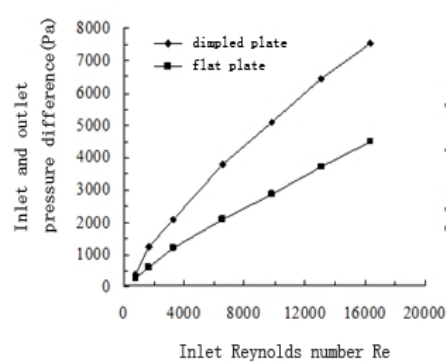

(a)Hot water inlet temperature $50^{\circ} \mathrm{C}$

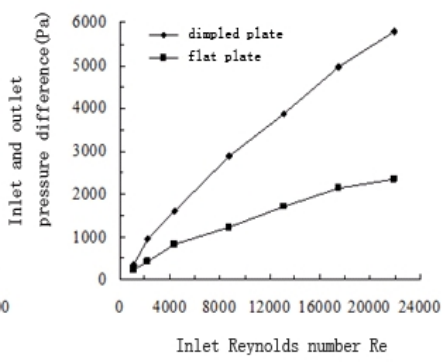

(b) Hot water inlet temperature $70^{\circ} \mathrm{C}$

Fig.7 Comparison of different entrance temperature dimpled plate and the plate pressure difference between the inlet and outlet of the $\Delta \mathrm{P}$ 


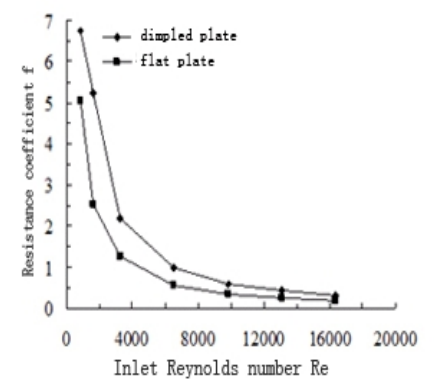

(a)Hot water inlet temperature $50^{\circ} \mathrm{C}$

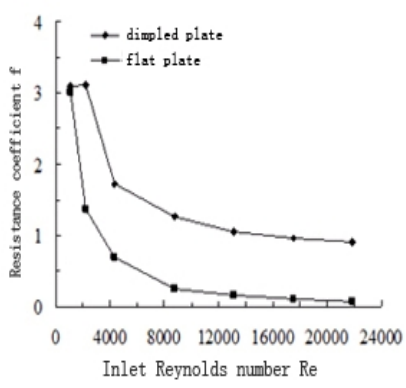

(b) Hot water inlet temperature $70^{\circ} \mathrm{C}$

Fig. 8 Comparison of dimpled plate and flat plate drag coefficient $f$ of entrance temperature

Can be seen from Figure 7 and 8, in the case of wall heat transfer, wall heat transfer coefficient and wall number are increase, inlet and outlet of the differential pressure is also increase, and the resistance will increase, and there is little effect on the change of the outlet temperature.

\section{CONCLUSION}

In this paper, the experimental research is conducted on the dimpled plate and flat plate respectively, and provid a detailed comparative analysis of the results, the following conclusions can be made:

(1) At the same inlet temperature, heat transfer is closely related to Reynolds, when the Reynolds number less than 2300, the heat transfer effect of dimpled plate is a little higher than flat plate; with increase Reynolds number, the wall heat transfer coefficient of dimpled plate is also increase, in the meantime, temperature difference between inlet and outlet become smaller and smaller.

(2)The heat transfer experiments are carried out for dimpled plate and flat plate at the inlet temperature of $50^{\circ} \mathrm{C}$ and $70^{\circ} \mathrm{C}$ respectively. Under the premise that the initial flow rate is controlled at $0.05 \mathrm{~m} / \mathrm{s}$ to $1 \mathrm{~m} / \mathrm{s}$, it is concluded that the different hot water outlet temperature and the change of inlet temperature has little effect on the heat transfer efficiency of dimpled plate, at $50{ }^{\circ} \mathrm{C}$ and $70{ }^{\circ} \mathrm{C}$ the change curves are consistent.

(3)For dimpled plate, with the heat transfer capability enhance the resistance of heat transfer will increase at the same time. In practical application process must be optimize the analysis when choosing dimpled plate and to find out a dimple plate with good matching effect between heat transfer enhancement and pressure loss.

\section{REFERENCES}

[1]YANG chonglin.Plate heat exchanger engineering design manual[M].Beijing: Design Manual,1994.

[27SHI meizhong.Heat exchanger principle and design[M].Southeast University,2002.

[3]AN yinghua.The application problems of plateheat exchanger in the the central heating sy stem[J].District heat supply.1989,(3):29-31.

[4]Kumar H.Condensation duties in plate heat exchangers[R].Symposium on condenser:theory andPractice.1989.

[5]Incropera,F.P.andDeWitt,D.P.1990, Fundamentals of Heat and Mass Transfer (3rd ed.). John Wiley \& Sons, Inc., New York.

[6]GU weizao, MA chongfang. Heat transfer enhancement[M].Beijing: science and technology Press, 1990.

[7]DONG chaojun.Plate Heat Exchanger Visualization Auxiliary system[J]. Journal of engine eringfor thermal energy and power,2001.

[8]Ji changfa,WANG yueyong,LIU xiaobing.Dimples heat exchange plate heat transfer enhan cement analysis[J].

[9]LIU jianyong,LI jing. Study of heat exchanger performance of a new type convex and concaveshell heat exchange plate formed passage under different combination modes[J]. Journal of engineering for thermal energy and power,2011,26(2):191-196. 